\title{
PENGEMBANGAN BUKU POP-UP KARIER UNTUK KESADARAN KARIER SISWA SEKOLAH DASAR
}

\author{
Elia Firda Mufidah ${ }^{1}$
}

\begin{abstract}
Abstrak
Kesadaran karier merupakan hal yang penting dimiliki siswa di sekolah dasar. Perkembangan karier di sekolah dasar menjadi tugas dari guru bimbingan dan konseling atau konselor kunjung. Media bimbingan dan konseling di sekolah dasar masih minim. Oleh karena itu peneliti mencoba mengembangan buku pop-up karier untuk membantu memberikan layanan bimbingan karier di sekolah dasar terutama dalam tahap kesadaran karier. Metode penelitian dan pengambangan yang digunakan ada 3 tahapan yakni studi pendahuluan, tahap pengembangan dan tahap uji media.
\end{abstract}

Kata Kunci: Kesadaran, Karier, dan Buku Pop-Up

\begin{abstract}
Career awareness is important for students in primary school. School career in elementary school becomes the duty of guidance and counseling teacher or counselor to visit. Guidance and counseling in primary schools is minimal. Therefore, you can develop career pop-up books to help provide guidance services in elementary schools in the career awareness process. Methods of research and mining used are 3 stages of preliminary study, development stage and media stages. Keywords: Awareness, Career, and Pop-Up Book
\end{abstract}

\section{PENDAHULUAN}

Kesadaran karier merupakan hal yang penting untuk dimiliki siswa di Sekolah Dasar. Hal tersebut sesuai dengan pandangan Mc Daniels \& Hummel (1984) ada 3 tahapan perkembangan karier anak yakni kesadaran (sebelum 11 tahun), eksplorasi (11 - 17 tahun) dan persiapan (17 tahun ke atas). Kesadaran karier memberikan landasan perkembangan karier individu kearah berikutnya. Pengembangan karier pada jejang Sekolah dasar beracuan pada konsep perkembangan karier merupakan proses yang terjadi seumur hidup (Magnuson \& Starr, 2000). Kesadaran karier menjadi hal yang bisa dipelajari atau dilatihkan, sehingga perlu adanya layanan karier untuk memaksimalkannya. Pada jenjang Sekolah Dasar, pemahaman karier diberikan bukan berfokus kepada kemampuan anak untuk mengambil keputusan secara dini tetapi untuk menjadikan dasar pengambilan keputusan pada tahap selanjutnya (Dimakakou, Mylonas, Argyropoulou, \& Drosos, 2013).

Kesadaran karier memerlukan dua konsep yang digabungkan menjadi satu, yakni konsep kesadaran dan karier. Konsep kesadaran salah satunya dijelaskan melalui pendekatan Gestalt dimana konsep kesadaran sebagai kunci untuk membuka wawasan dan akhirnya membawa perubahan perilaku (Zimberoff \& Hartman, 2003). Selain itu, Perls (Pedersen, 2010) menjelaskan bahwa kesadaran diperoleh dari siklus pengalaman yang merupakan siklus ketergantungan antara individu dengan lingkungannya. Hal tersebut menjelaskan bahwa anak sekolah dasar dalam mencapai kesadaran kariernya membutuhkan interaksi dengan lingkungan

\footnotetext{
${ }^{1}$ Universitas PGRI Adi Buana Surabaya, eliafirda@unipasby.ac.id
} 
yang diwakili oleh guru bimbingan dan konseling. Tentunya dalam interaksi tersebut harus menggunakan aturan dan konsep karier dalam implementasinya untuk membentuk perilaku yang mencerminkan siswa sudah memiliki kesadaran karier.

Di Sekolah Dasar terdapat konselor kunjung dalam melaksanakan layanan bimbingan dan konseling. Media bimbingan dan konseling di ranah Sekolah Dasar masih minim pengembangannya. Begitupun pemberian layanan bimbingan dan konseling yang masih menyesuaikan dengan peraturan untuk implementasinya. Penggunaan media akan menjadi daya tarik tersendiri untuk siswa. Hal tersebut mengingat posisi siswa Sekolah Dasar masih dalam ranah kanak-kanak akhir sehingga dalam pemberian layanan membutuhkan media untuk menarik perhatian siswa sekolah dasar. Buku pop-up masih menjadi hal yang baru dalam pengembangan media buku bacaan. Buku pop-up memberikan kemenarikan tersendiri dalam penggunaannya. Unsur 3 dimensi, penggunaan warna yang meriah dan bentuk yang unik memudahkan individu dalam memahami dari buku tersebut. Kesadaran karier akan terbentuk dengan menggunakan media buku pop-up karier karena buku popup karier menuntut siswa untuk berinteraksi dengan guru bimbingan dan konseling. Interkasi tersebut tentunya harus berdasarkan pedoman yang berhubungan dengan karier.

\section{METODE PENELITIAN}

Prosedur penelitian yang digunakan peneliti dalam pengembangan ini diadaptasi dari langkah-langkah pengembangan yang dikembangkan oleh Gall (2003), penerapannya disesuaikan dengan kebutuhan peneliti. Dari beberapa langkah pengembangan Borg and Gall, peneliti membaginya menjadi 3 tahapan secara umum (Sukmadinata, 2012) yakni: (1) Studi Pendahuluan, (2) Tahap pengembangan media, (3) Tahap uji media.

Studi pendahuluan berisikan survey lapangan dan studi kepustakaan. Survei lapangan dilakukan untuk mengumpulkan data sebagai bahan perencanaan dan pelaksanaan dalam penelitian dan pengambangan ini. Data yang dikumpulkan diperoleh melalui wawancara dan observasi. Dari hasil wawancara dari salah satu Guru di SD IT Mutiara Hati diperoleh data bahwa siswa kelas $\mathrm{V}$ memiliki tingkat kesadaran karier yang masi rendah. Hal tersebut terlihat dari jawaban pertanyaan tentang apa cita-cita dari mereka yang masih ragu-ragu. Kemudian ketika diminta untuk menjelaskan bagaimana cita-citanya diperoleh gambaran yang belum spesfik. Selain itu tingkat minat membaca siswa masih rendah yang terlihat dari kedatangan siswa ke perpustakaan jumlahnya sedikit untuk siswa kelas V. Studi kepustakaan merupakan kajian yang dilakukan untuk mempelajari teori-teori yang berhubungan dengan produk atau draf media yang akan dikembangkan. Berdasarkan survey lapangan diketahui bahwa kesadaran karier siswa masih perlu ditingkatkan dan perlu dikembangkan media Bimbingan dan Konseling untuk kesadaran karier. Oleh karena itu dalam studi kepustakaan ini difokuskan untuk mengkaji konsep dan teori yang berkenaan dengan media Bimbingan dan Konseling, buku pop-up, kesadaran karier dan penelitian-penelitian terdahulu yang sesuai dengan pembuatan media ini.

Setelah melakukan survey dan studi kepustakaan maka dilakukan perencanaan penyusunan produk awal. Perencanaan penyusunan produk awal didasarkan pada hasil survey lapangan dan studi kepustakaan kemudian didukung oleh penelitian terdahulu yang mengungkapkan bahwa media yang perlu dikembangan harus bersifat interaktif.

Uji ahli dilakukan oleh dua orang ahli BK dan pengembangan media pendidikan. Uji pengguna dilakukan melalui satu guru Bimbingan dan Konseling. Uji lapangan terbatas dilakukan pada subjek sasaran penelitian. Uji coba ini dilakukan menggunakan buku pop-up karier untuk mengetahui perbedaan kesadaran karier siswa sebelum dan sesudah menggunakan 
buku pop-up karier. Desain yang digunakan yakni pretest and posttest group design.

\section{HASIL PENELITIAN}

Uji ahli dilakukan oleh 2 ahli Bimbingan dan Konseling serta 2 ahli pengembangan media pendidikan. Uji ahli Bimbingan dan Konseling dilakukan oleh Dr. Triyono, M.Pd dan Boy Soedarmadji, S.Pd., M.Pd, sedangkan uji ahli pengembangan media pendidikan dilakukan oleh Prof. Dr. Punaji Setyosari, M.Pd., M.Ed dan Dr. M. Subandowo, M.Si. Uji ahli Bimbingan dan Konseling difokuskan pada isi atau materi media buku pop-up karier, sedangkan uji ahli pengembangan media pendidikan difokuskan pada visualisasi buku pop-up karier.

\begin{tabular}{|c|c|c|c|c|}
\hline \multirow[b]{2}{*}{ No } & \multirow[b]{2}{*}{ Aspek yang dinilai } & \multicolumn{2}{|c|}{ Penilaian } & \multirow[b]{2}{*}{ Ket } \\
\hline & & $\begin{array}{c}\text { Ahli } \\
1\end{array}$ & $\begin{array}{c}\text { Ahli } \\
2\end{array}$ & \\
\hline & Ketepatan & & & \\
\hline 1 & $\begin{array}{l}\text { Ketepatan penggunaan } \\
\text { bahasa dengan } \\
\text { kemampuan siswa } \\
\text { Sekolah Dasar }\end{array}$ & 4 & 3 & $\mathrm{D}$ \\
\hline 2 & $\begin{array}{l}\text { Ketepatan pemilihan } \\
\text { jenis huruf dan ukuran } \\
\text { huruf }\end{array}$ & 3 & 2 & B \\
\hline 3 & $\begin{array}{l}\text { Ketepatan pemilihan } \\
\text { gambar dan pemberian } \\
\text { makna }\end{array}$ & 4 & 3 & $\mathrm{D}$ \\
\hline 4 & $\begin{array}{l}\text { Ketepatan Buku pop- } \\
\text { upkarier dengan teori } \\
\text { karier }\end{array}$ & 4 & 3 & $\mathrm{D}$ \\
\hline & Kegunaan & & & \\
\hline 5 & $\begin{array}{l}\text { Penggunaan konsep } 3 \\
\text { dimensi dalam buku } \\
\text { pop-up karier }\end{array}$ & 4 & 3 & $\mathrm{D}$ \\
\hline 6 & $\begin{array}{l}\text { Penggunaan ilustrasi } \\
\text { yang ada dalam buku } \\
\text { pop-up karier }\end{array}$ & 4 & 3 & $\mathrm{D}$ \\
\hline 7 & $\begin{array}{l}\text { Pemilihan materi karier } \\
\text { untuk siswa Sekolah } \\
\text { Dasar }\end{array}$ & 4 & 3 & $\mathrm{D}$ \\
\hline 8 & $\begin{array}{l}\text { Kegunaan media buku } \\
\text { pop-upkarier untuk } \\
\text { memfasilitasi layanan } \\
\text { bimbingan karier di } \\
\text { Sekolah Dasar }\end{array}$ & 3 & 2 & $\mathrm{~B}$ \\
\hline 9 & $\begin{array}{l}\text { Penggambaran jenjang } \\
\text { pendidikan dalam } \\
\text { mempermudah siswa } \\
\text { untuk memahami karier }\end{array}$ & 3 & 3 & $\mathrm{D}$ \\
\hline
\end{tabular}

\begin{tabular}{|c|c|c|c|c|}
\hline \multirow[b]{2}{*}{ No } & \multirow[b]{2}{*}{ Aspek yang dinilai } & \multicolumn{2}{|c|}{ Penilaian } & \multirow[b]{2}{*}{ Ket } \\
\hline & & $\begin{array}{c}\text { Ahli } \\
1\end{array}$ & $\begin{array}{c}\text { Ahli } \\
2\end{array}$ & \\
\hline 10 & $\begin{array}{l}\text { Konsep kesadaran karier } \\
\text { yang dimunculkan dalam } \\
\text { bentuk tugas mandiri }\end{array}$ & 3 & 3 & $\mathrm{D}$ \\
\hline 11 & $\begin{array}{l}\text { Pemberian reward dari } \\
\text { tugas mandiri yang ada } \\
\text { dibuku }\end{array}$ & 3 & 3 & $\mathrm{D}$ \\
\hline \multicolumn{5}{|c|}{ Kelayakan } \\
\hline 12 & $\begin{array}{l}\text { Kemudahan dalam } \\
\text { memahami isi buku pop- } \\
\text { up karier }\end{array}$ & 4 & 3 & $\mathrm{D}$ \\
\hline 13 & $\begin{array}{l}\text { Ilustrasi pada buku } \\
\text { mudah untuk dipahami }\end{array}$ & 4 & 3 & $\mathrm{D}$ \\
\hline 14 & $\begin{array}{l}\text { Uraian materi yang ada } \\
\text { dalam buku pop-upkarier }\end{array}$ & 4 & 3 & $\mathrm{D}$ \\
\hline \multicolumn{5}{|c|}{ Kemenarikan } \\
\hline 15 & $\begin{array}{l}\text { Kemenarikan tampilan } \\
\text { cover dan isi buku pop- } \\
\text { up karier }\end{array}$ & 4 & 3 & $\mathrm{D}$ \\
\hline 16 & Visualisasi 3 dimensi & 4 & 3 & $\mathrm{D}$ \\
\hline 17 & $\begin{array}{l}\text { Bentuk hadiah yang } \\
\text { diberikan }\end{array}$ & 4 & 3 & $\mathrm{D}$ \\
\hline
\end{tabular}

Tabel 1. Data Penilaian Ahli Materi

Berdasarkan tabel diatas maka jumlah penilaian yang memiliki relevansi rendah dari ahli 1 dan ahli $2(\mathrm{~A})=0$, yang memiliki relevansi tinggi dari ahli 1 dan relevansi rendah dari ahli $2(\mathrm{~B})=2$, yang memiliki relevansi rendah dari ahli 1 dan relevansi rendah ahli $2(\mathrm{C})=0$ dan yang memiliki relevansi tinggi dari ahli 1 dan ahli 2 (D) = 15. Untuk proses kuantifikasi hasil dari uji ahli materi dengan menggunakan interagreement model sebagai berikut:

\begin{tabular}{|c|c|c|c|}
\hline & & \multicolumn{2}{|c|}{ PENDAPAT AHLI 1} \\
\hline & & $\begin{array}{c}\text { Relevansi } \\
\text { Rendah } \\
(1-2)\end{array}$ & $\begin{array}{l}\text { Relevansi } \\
\text { Tinggi (3- } \\
\text { 4) }\end{array}$ \\
\hline PENDAPAT & $\begin{array}{c}\text { Relevansi } \\
\text { Rendah } \\
(1-2)\end{array}$ & 0 & 2 \\
\hline AHLI 2 & $\begin{array}{c}\text { Relevansi } \\
\text { Tinggi } \\
(3-4)\end{array}$ & 0 & 15 \\
\hline
\end{tabular}

Tabel 2. Kuantifikasi hasil uji ahli materi

Penentuan indeks uji ahli materi menggunakan rumus $=15 /(0+2+0+15)=$ $15 / 17=0,88$. Indeks uji ahli materi menunjukkan sebesar 1 dimana masuk 
dalam rentang nilai $0,66-1,00$. Maka menurut penilaian ahli materi mengenai keberterimaan media BUKARIER baik atau layak diterima untuk digunakan.

Ahli media 1 tidak memberikan masukan hanya berkomentar sudah baik ketika pengembang mengambil hasil validasi produk. Sedangkan masukan dari ahli materi 2 yakni penggunaan bahasa dalam BUKARIER lebih disesuaikan dengan bahasa siswa sekolah dasar. Masukan dari ahli materi digunakan untuk menyempurnakan isi dari media BUKARIER yakni memperbaiki penggunaan kalimat dalam BUKARIER agar lebih bisa dipahami oleh siswa sekolah dasar.

\begin{tabular}{|c|c|c|c|c|}
\hline \multirow[b]{2}{*}{ No } & \multirow[b]{2}{*}{ Aspek yang dinilai } & \multicolumn{2}{|c|}{ Penilaian } & \multirow[b]{2}{*}{ Ket } \\
\hline & & $\begin{array}{c}\text { Ahli } \\
1\end{array}$ & $\begin{array}{c}\text { Ahli } \\
2\end{array}$ & \\
\hline & Ketepatan & & & \\
\hline 1 & $\begin{array}{l}\text { Ketepatan } \\
\text { penggunaan bahasa } \\
\text { dengan kemampuan } \\
\text { siswa Sekolah } \\
\text { Dasar }\end{array}$ & 3 & 2 & B \\
\hline 2 & $\begin{array}{l}\text { Ketepatan } \\
\text { pemilihan jenis } \\
\text { huruf dan ukuran } \\
\text { huruf }\end{array}$ & 3 & 2 & $\mathrm{~B}$ \\
\hline 3 & $\begin{array}{l}\text { Ketepatan } \\
\text { pemilihan gambar } \\
\text { dan pemberian } \\
\text { makna }\end{array}$ & 4 & 4 & $\mathrm{D}$ \\
\hline 4 & $\begin{array}{l}\text { Ketepatan Buku } \\
\text { pop-upkarier } \\
\text { dengan teori karier }\end{array}$ & 3 & 3 & $\mathrm{D}$ \\
\hline & Kegunaan & & & \\
\hline 5 & $\begin{array}{l}\text { Penggunaan konsep } \\
3 \text { dimensi dalam } \\
\text { buku pop-up karier }\end{array}$ & 3 & 3 & $\mathrm{D}$ \\
\hline 6 & $\begin{array}{l}\text { Penggunaan } \\
\text { ilustrasi yang ada } \\
\text { dalam buku pop-up } \\
\text { karier }\end{array}$ & 3 & 3 & $\mathrm{D}$ \\
\hline 7 & $\begin{array}{l}\text { Pemilihan materi } \\
\text { karier untuk siswa } \\
\text { Sekolah Dasar }\end{array}$ & 3 & 3 & $\mathrm{D}$ \\
\hline 8 & $\begin{array}{l}\text { Kegunaan media } \\
\text { buku pop-upkarier } \\
\text { untuk memfasilitasi } \\
\text { layanan bimbingan } \\
\text { karier di Sekolah } \\
\text { Dasar }\end{array}$ & 4 & 4 & $\mathrm{D}$ \\
\hline 9 & $\begin{array}{l}\text { Penggambaran } \\
\text { jenjang pendidikan }\end{array}$ & 3 & 3 & $\mathrm{D}$ \\
\hline
\end{tabular}

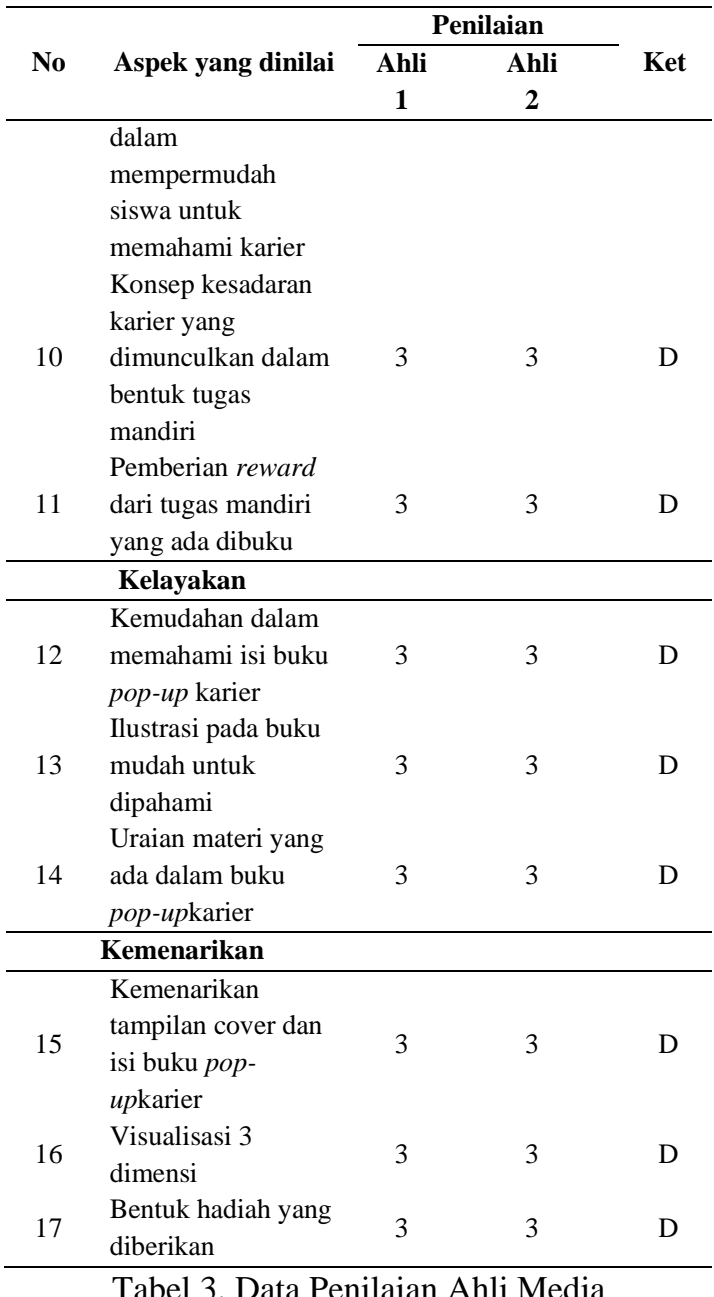

Tabel 3. Data Penilaian Ahli Media

Dari data tabel 4.2 diperoleh hasil jumlah penilaian yang memiliki relevansi rendah dari ahli 1 dan $2(\mathrm{~A})=0$, yang memiliki relevansi tinggi dari ahli 1 dan relevansi rendah dari ahli 2 (B) $=2$, yang memiliki relevansi rendah dari ahli 1 dan relevansi tinggi dari ahli $2(\mathrm{C})=0$, dan yang memiliki relevansi tinggi dari ahli 1 dan ahli $2(D)=15$. Proses kuantifikasi hasil uji ahli media dengan menggunakan interagreement model sebagai berikut:

\begin{tabular}{|c|c|c|c|}
\hline & & \multicolumn{2}{|c|}{ PENDAPAT AHLI 1} \\
\hline & & $\begin{array}{c}\text { Relevansi } \\
\text { Rendah } \\
(1-2)\end{array}$ & $\begin{array}{c}\text { Relevansi } \\
\text { Tinggi } \\
(3-4)\end{array}$ \\
\hline PENDAPAT & $\begin{array}{c}\text { Relevansi } \\
\text { Rendah } \\
(1-2)\end{array}$ & 0 & 2 \\
\hline AHLI 2 & $\begin{array}{c}\text { Relevansi } \\
\text { Tinggi } \\
(3-4)\end{array}$ & 0 & 15 \\
\hline
\end{tabular}


Tabel 4. Kuantifikasi hasil uji ahli media

Perhitungan indeks uji ahli menggunakan rumus $15 /(0+2+0+15)=15 / 17$ $=0,88$. Indeks uji ahli media menunjukkan hasil 0,88 masuk dalam kriteria pertama dengan rentang nilai $0,66-1,00$. Dari hasil tersebut maka penilaian dari ahli pengembangan media pendidikan mengenai keberterimaan media BUKARIER dapat dikatakan bahwa media BUKARIER baik atau layak untuk diterima atau digunakan.

Ahli media 1 memberikan masukan akan lebih baik jika dibagian awal buku ada prakata, daftar isi dan tujuan, sebaga satu kesatuan gambar di sampul sebaiknya sama, dan buku sudah bagus. Sedangkan masukan dari ahli materi 2 yakni penggunaan bahasa dalam BUKARIER sebaiknya bahasa anak dimana tingkat serapan dan gaya komunikasi sangat perlu diperhatikan.

Hasil uji ahli dalam pembahasan ini meliputi uji ahli media dan materi. Menurut para ahli media dan materi titik tekan yang perlu diperbaiki adalah penggunaan bahasa. Berkaitan dengan penggunaan bahasa pada BUKARIER sebelumnya pengembang sudah melakukan tes keterbacaan terhadap BUKARIER di 2 sekolahan yang berbeda yakni SD IT Mutiara Hati dan SD N Masangan dan siswa sudah mengungkapkan tidak ada masalah dengan penggunaan bahasa dalam BUKARIER. Sehingga untuk perbaikan penggunaan bahasa difokuskan pada keinteraktifan kalimat yang ada dalam BUKARIER. Hal ini yang menjadi permasalahan yang perlu untuk dikaji kembali tentang konstruk pemahaman verbal anak sekolah dasar pada era sekarang. Kemudahan akses teknologi informasi oleh siswa sekarang menambah kosakata dan konstruk bahasa yang mereka miliki. Seperti halnya kata "pop-up 3 dimensi" yang dikhawatirkan sebelumnya tidak dipahami oleh siswa sekolah dasar ternyata siswa sudah memahami maksud dari pop-up 3 dimensi sebagai salah satu bentuk buku yang bisa berdiri dan berbentuk tiga dimensi. Hal tersebut mengindikasikan terjadinya literasi digital pada anak. Literasi digital bisa terlihat dari hasil penelitian Pratiwi dan
Pritanova (2017) yang memberikan gambaran bagaimana anak memperoleh dampak dari era digital. Tidak hanya dampak negative yang terlihat tapi kemampuan verbal dan nonverbal anak menjadi lebih luas karena mudahnya anak memahami suatu hal hanya dengan mengakses media online.

Dari hasil saran ahli media dan materi maka perbaikan yang dilakukan dalam BUKARIER yakni perubahan bahasa yang digunakan. Perubahan tersebut tidak merubah konteks pembahasan dari setiap halaman tetepi pengembang mengubah bahasa yang digunakan menjadi lebih interaktif. Pengembang mengajak pembaca seakan sedang berinteraksi dalam suau pembicaraan sehingga anak lebih bisa memahami apa yang menjadi maksud dari pengembang.

Hasil penilaian para ahli dari hasil kuantifikasi yang telah dipaparkan pada BAB IV dapat dinilai bahwa media BUKARIER telah layak atau dapat diterima sebagai media bimbingan dan konseling di sekolah dasar dalam layanan bimbingan karier. Hal tersebut terlihat dari penilaian angka yang diberikan oleh para ahli. Perhitungan hasil kuesioner yang diisi oleh para ahli menggunakan perhitungan interagreement model karena menggabungkan kesepakatan 2 ahli.

Kelayakan tersebut diperoleh pengembang karena menggunakan dasar konsep tool of mind dari teori konstruktivisme Vygotsky. Konsep scaffolding memiliki teknik "Tool of Mind" yang merupakan bentuk untuk mendukung kognitif yang berfokus pada pengembangan dari sejumlah alat pengajaran untuk mendukung proses belajar yang diberikan untuk membuat metode yang unik (Bodrova, Germeroth, \& Leong, 2013). Selain itu ada beberapa penelitian yang menjadi acuan pengembang membuat BUKARIER dengan menggunakan unsur pop-up yakni penelitian dari Setyawan (2014) menjelaskan bahwa media pop-up bisa meningkatkan keterampilan berbicara pada anak SD 1 Wonoharjo. Seperti halnya katerampilan 
berbicara yang bisa dilatihkan, kesadaran karier juga bisa dilatihkan karena terjadi dari proses belajar berinteraksi dengan lingkungan dimana guru bimbingan dan konseling menjadi pengganti dari lingkungan.

Selain itu, BUKARIER juga dihubungkan dengan kriteria dalam pemilihan media bimbingan dan konseling yang digunakan (Nursalim, 2013) yakni 1) kesesuaian dengan tujuan dan materi bimbingan serta teori, hal tersebut terlihat dari adanya tujuan dalam BUKARIER untuk memberikan kesadaran karier siswa SD dalam SKKPD; 2) kejelasan dalam latar belakang yang dipaparkan dalam panduan yang harus diperhatikan supaya pengguna dapat memahami maksud dan tujuan dari pengembangan media; 3) pengemasan media supaya tampak rapi, hal ini sesuai dengan kemasan dan tampilan BUKARIER yang menggunakan unsur 3 dimensi atau pop-up untuk bisa menarik dan rapi; 4) efisien waktu bimbingan.

Penggunaan unsur 3 dimensi atau popup pada BUKARIER didasarkan pada prinsip visualisasi media yakni kesederhanaan, keterpaduan, penekanan dan keseimbangan, serta memperhatikan unsur visualisasi lain seperti garis, ruang dan tekstur (Arsyad, 2011). Pada akhirnya kuesioner penilaian ahli didasarkan pada unsur kegunaan, kelayakan, ketepatan dan kemenarikan. Hasil yang diperoleh dari kuesioner penilaian tersebut menunjukkan indeks uji ahli yang tinggi yakni 1 yang diartikan bahwa menurut para ahli media BUKARIER telah memenuhi kriteria pemilihan media BK dan layak menjadi media bimbingan dan konseling yang digunakan untuk meningkatkan kesadaran karier siswa Sekolah Dasar.

Berdasarkan hasil uji pengguna BUKARIER diperoleh hasil bahwa BUKARIER sudah cukup bagus untuk digunakan sebagai media bimbingan dan konseling dalam layanan bimbingan karier. Hal tersebut mengingat belum banyaknya media yang bisa digunakan untuk memberikan layanan pada jenjang sekolah dasar selain permasalahan konselor kunjung pada tingkat sekolah dasar. Namun diperoleh temuan di lapangan adanya permasalahan seputar penggunaan gambar yang ada di BUKARIER. Latar belakang pendidikan agama yang ditekankan pada sekolahan ini membentuk siswa memiliki prinsip yang lebih terhadap hal yang baik dan buruk. Gambar dalam BUKARIER untuk visualisasi tokoh yang ada jika perempuan perlu dirubah menjadi lebih sopan dengan berkerudung. Selain itu penggunaan salam secara islami perlu ditambahkan. Hal-hal tersebut yang dirubah dari BUKARIER sehingga BUKARIER ada tambahan dalam hal penggunaan salam pembuka, perubahan icon gambar yang lebih islami dan salam penutup.

$\begin{array}{ccl}\text { Konselor } & \text { sebelum } & \text { menggunakan } \\ \text { BUKARIER } & \text { mengalami } & \text { kekhawatiran. } \\ \text { Kekhawatiran } & \text { tersebut } & \text { yakni guru }\end{array}$ bimbingan dan konseling memiliki pandangan tidak yakin dengan bahasa yang digunakan dalam BUKARIER tetapi ketika buku tersebut diberikan kepada siswa ternyata siswa sudah bisa memahami tiap kata yang digunakan dalam BUKARIER. Penggunaan ukuran huruf pada BUKARIER juga perlu diperhatikan agar karena ukuran BUKARIER yang tidak terlalu besar. Hal tersebut digunakan acuan dalam perbaikan BUKARIER sehingga tulisan yang ada dalam BUKARIER direvisi dan diperbesar.

Penilaian keberterimaan media BUKARIER oleh guru bimbingan dan konseling didasarkan pada hasil need assesement. Hasil tersebut diperoleh dari hasil wawancara akan ketersediaan media pendukung untuk pemberian layanan bimbingan dan konseling di sekolah dasar. Selama ini layanan bimbingan dan konseling diberikan hanya melalui penggunaan media video dan belum ada yang bisa disentuh langsung oleh siswa dan bisa diamati siswa dari dekat. Bimbingan karier menjadi hal yang penting karena perlu ada konstruk baru dalam pandangan siswa mengenai karier yang harus disiapkan sejak dini. Alasan ini yang menjadi salah satu dasar penyusunan media BUKARIER. 
Berdasarkan kuantifikasi penilaian uji pengguna dengan satu guru bimbingan dan konseling/konselor dipperoleh hasil perhitungan prosentasi uji pengguna sebesar $88,23 \%$. Hasil tersebut masuk dalam kriteria sangat valid atau dapat digunakan tanpa revisi. Meskipun perhitungan yang diperoleh menunjukkan tanpa revisi namun masih ada beberapa perbaikan saran yang sudah diberikan oleh guru bimbingan dan konseling/konselor. Konselor mengungkapkan bahwa unsur pop-up dari BUKARIER menjadi nilai lebih. Seperti halnya penelitian dari Praditya dan Nursalim (2016) menunjukkan bahwa media pop-up untuk pengenalan karier memenuhi kriteria dari aspek kelayakan. Penilaian yang diperoleh yakni ahli media sebanyak $91 \%$, ahli materi sebanyak 92\%, dan calon pengguna sebanyak 96\%. Rata-rata nilai keseluruhan sebesar 93\%, sehingga kategori nilai yang diperoleh sangat baik, tidak perlu direvisi. Kesimpulannya yakni media popup tentang pengenalan karier telah memenuhi keiteria aspek kelayakan sehingga bisa digunakan oleh siswa kelas III SDN Tambakagung Puri Mojokerto.

\section{KESIMPULAN}

BUKARIER membentuk kesadaran karier dalam bentuk interaksi yang dilakukan siswa. Interaksi yang dilakukan berdasarkan indikator karier yang sudah ditentukan. BUKARIER mengarahkan siswa tentang karier apa yang diinginkannya dengan merinci hal-hal apa saja yang harus dilakukan siswa mulai dari jenjang pendidikan yang mereka lalui sampai pada hal-hal apa saja yang harus disiapkan oleh siswa sejak dini. Dari segi validitas dari BUKARIER, hasil para uji ahli menyatakan bahwa BUKARIER layak digunakan sebagai media dalam bimbingan karier di sekolah dasar tentunya dengan beberapa revisi yang sudah dilakukan oleh pengembang.

Produk pengembangan media BUKARIER dapat dimanfaakan secara maksimal tetapi perlu adanya beberapa perbaikan diantaranya:
Media ini baik digunakan secara individu agar masing-masing siswa bisa memahami isi dari BUKARIER

Siswa diharapkan membaca literature lain terkait karier untuk menambah pengetahuan seputar karier

Saran pengembangan produk lebih lanjut sebagai berikut:

Produk yang dikembangkan perlu dilakukan uji coba kelompok besar karena pengembang sudah melakukan uji coba kelompok kecil sesuai dengan tahapan penelitian Borg dan Gall

Diharapkan nantinya BUKARIER bisa dibuat dalam versi digital untuk memudahkan akses siswa dalam memahami karier

\section{DAFTAR PUSTAKA}

Arsyad, A. (2011). Media Pembelajaran. Jakarta: Rajawali Press.

Bodrova, E., Germeroth, C., \& Leong, D. (2013). Play and self-regulation: Lessons from Vygotsky. American Journal of Play, 6, 111-123.

Dimakakou, D. S., Mylonas, K., Argyropoulou, K., \& Drosos, N. (2013). Career Decision-Making Characteristics of Primary Education Students in Greece. International Education Studies, 6(5). https://doi.org/10.5539/ies.v6n5p22

Gall, M., Gall, J., \& Borg, W. (2003). Educational Research. Boston: Pearson Education, Inc.

Magnuson, C. S., \& Starr, M. F. (2000). How Early Is Too Early to Begin Life Career Planning? The Importance of the Elementary School Years. Journal of Career Development, 27(2), 89101. https://doi.org/10.1177/089484530002 700203

Nursalim, M. (2013). Pengembangan Media Bimbingan dan Konseling. Jakarta: Akademia Permata.

Pedersen, T. (2010). Touch or no Touch An interpretative phenomenological analysis of gestalt therapists and their 
experiences with physical touch in the therapeutical session. Derby,

England: University of Derby.

Praditya, S. Y., \& Nursalim, M. (2016).

Pengembangan Media Pop Up

Pengenalan Karir untuk Siswa Kelas

III SDN Tambakagung Puri

Mojokerto. Jurnal BK UNESA, 6(1), $1-10$.

Pratiwi, N., \& Pritanova, N. (2017).

Pengaruh Literasi Digital Terhadap

Psikologis Anak dan Remaja.

Semantik, 6(1), 11.

https://doi.org/10.22460/semantik.v6i

1.p11-24

Setyawan, D., \& Usada \& Mahfud, H.

(2014). Penerapan Media Pop-Up

Book untuk Meningkatkan

Keterampilan Berbicara. Jurnal

Didaktika Dwija Indria, 2(11), 1-5.

Sukmadinata, N. S. (2012). Metode

Penelitian Pendidikan. Bandung:

Remaja Rosdakarya.

Zimberoff, D., \& Hartman, D. (2003).

Gestalt therapy and Heart-Centered

therapies. Journal of Heart Centered

Therapies, 6, 93-104. 